\title{
NOVAS AURORAS AO FEMINISMO: NÓS VAMOS QUEBRAR AS PAREDES!
}

\author{
NEW DAYSPRINGS TO FEMINISM: LET'S BREAK THE WALLS!
}

\section{RESUMO}

Este artigo busca propor reflexões sobre o feminismo como uma práxis desdobrada a partir do fazer artístico e de estratégias políticas de uso da linguagem, partindo da noção de representação artística e do exemplo de um trabalho com o coletivo Bárbara Idade (grupo de teatro composto por atrizes senescentes) e de algumas referências literárias usadas para a criação desta dramaturgia em paralelo com o pensamento de Butler (2013); Adichie (2009; 2015); Preciado (2014); Hanisch (2000) entre outros, no sentido de fortalecer interseccionalidades efetivas para além das demandas específicas de grupos dentro do feminismo (mulheres trans; negras; lésbicas) com o objetivo de provocar um pensamento feminista abrangente e plural.

Palavras-chave: Feminismo. Interseccionalidade. Gênero. Representação. Teatro.

\section{ABSTRACT}

This article seeks to propose reflections on feminism as a praxis deployed from the artistic and political strategies of language use, starting from the notion of artistic representation and the example of a work with the collective Bárbara Idade (theater group composed of senescent actresses) and some literary references used for the creation of this dramaturgy in parallel with the thought of Butler (2013); Adichie (2009; 2015); Preciado (2014); Hanisch (2000), among others, in order to strengthen effective intersectionalities beyond the specific demands of groups within feminism (transgender women, ethnic and black woman; lesbians) with the aim of provoking comprehensive and plural feminist thinking.

Keywords: Feminism. Intersectionality. Gender. Representation. Theater.
À Lina (Trupe Chá de Boldo)
Para depois da tempestade
Para um novo amor chegar
Para que entrem os insetos
Para aqui dentro desembolorar
Para ver melhor a lua
Para a rua poder entrar
Para assistir ao beijo na esquina
Para a menina tomar um ar
Para quem curte o sol
Para quem quer se soltar 
Para que as plantas todas

Aos poucos possam se aproximar

Eu quero quebrar as paredes

Nós vamos quebrar

"Não dispenso a chance de manifestar-me na expansão do meu feminino, que é peculiar, que é único. Meu trabalho é o de uma mulher no século XX. Como não ser especial? Não, não dispenso meu trilho do feminino. Temos toda a História sendo escrita. Somos novas, frescas e fortes." (STOKLOS, Denise. 1993: 10 Teatro Essencial)

É preciso, sim, seguir a falar mais uma vez (e tantas quantas forem necessárias) sobre este tema tão ancestral quanto atual: o feminino, o feminismo, as intersecções todas que se precisa trazerà tona para dar conta de um universo complexo e diversificado de demandas, vozes individuais que apontam questões coletivas sempre; pois que cada mulher, desde ancestral e atualmente, calada ou violentada resvala em todas as mulheres, nas opressões sistemáticas partilhadas. Por isso abro invocando a canção do grupo Chá de Boldo (coletivo misto de homens e mulheres atuante na cena musical brasileira atual) e as palavras de Denise Stoklos, já uma consagrada atriz, dramaturga e diretora de nosso teatro, com repercussão e reconhecimento internacionais, para compartilhar algumas das minhas inquietações partindo da articulação basilar entre feminismo e estudos de gênero, com uma sinalização precisa à perspectiva trans, por mim aqui entendida no diapasão fundamental da interseccionalidade: feminismo $S$ pluralizadamente, o que inclui podermos estar acolhidas ao debate todas, sejamos literalmente transgêneras ou não; pois que devemos todas nos abrir às reflexões que, em última instância, nos conduzam ao humano e suas infindáveis potências/ peculiaridades. Assim é que, de imediato, a minha fala aqui já começou a revelar corpo.

Invoco Virginia Woolf (1928: 07), em seu ensaio Um Teto todo seu: "Mas, dirão vocês, nós lhe pedimos que falasse sobre as mulheres e a ficção - o que tem isso a ver com um teto todo seu?" E adapto, devidamente: instando neste artigo uma reflexão sobre "Transfeminismos e representações literárias"; como isso se relaciona com as proposições de Woolf e com um dos exemplos que trarei à discussão? Que nosso percurso se faça como se dança uma ciranda: circular, todas de mãos dadas e em confluências (mesmo nas eventuais e necessárias discordâncias).

Não sou Transmulher, no sentido que o prefixo trans assinala quando indicador de pessoa em transição de gênero: que seria aquela que nasce e é (como a heteronorma convencionou) identificada a um gênero que "corresponde" à genitália que este corpo exibe; ou ao padrão cromossômico XX; XY... Como se a complexidade a que chegamos em nossas construções como seres individuais e em relações de coletividade e de poder não fossem mais que bastantes para percebermos que cristalizações identitárias nem remotamente dão conta desta tarefa. 
Eis que para pensar de forma mais arguta ou sagaz essa questão identitária dos gêneros, autoras como Judith Butler e Paul (Beatriz) Preciado são ferramentas excelentes. Ambas, em seus percursos (que se atravessam), propõem elementos instigantes para novas formas de se considerar a questão. Em comum, de modo bastante resumido, ambas denunciam a estratégia de poder e controle dos corpos (visão em que avançam a partir do pensamento de Michel Foucault, deve-se assinalar, o qual trabalha a lógica de vigilância e punição sobre os corpos e a heteronormatividade compulsória das sociedades capitalistas desde a era vitoriana: confira-se, entre outros, sua imprescindível História da sexualidade (1988, em 3 volumes).

Então, a proposição do gênero como performance e performatividade, elaborada por Butler (conferir, entre outros livros da autora, o Problemas de gênero: feminismo e subversão da identidade), associa as nuances de gênero a fatores múltiplos e políticos, com base no desejo e na construção da subjetividade individual e relacional, ou seja, a sociedade capitalista cria estratégias de 'naturalização' de conceitos que são, conforme denuncia e demonstra Butler, construções culturais: a estereotipia de comportamentos, vestimentas, modos de falar estabelecidos como 'naturais' de cada um dos gêneros (apenas binariamente estabelecidos) do masculino e feminino não leva em consideração divergências e multiplicidades individuais/ culturas e convicções de grupos. Assim, se estabelece a 'ficção' de um comportamento unívoco que deve ser comum e seguido por homens e mulheres para se verem adequados à suposta coincidência de genitália e performance de gênero, para além de todos os outros traços particularizantes da vivência e das crenças da pessoa em questão. Dessa forma, Butler denuncia que o gênero se resume a uma performance, a uma atuação em acordo ou desacordo com a imposição comportamental heteronormativa e binária.

E seguindo nessa discussão, Preciado radicaliza na estratégia de denúncia da tutela de corpos e comportamentos e da artificialidade que rege o confisco das instâncias de poder: a sexualidade fica restrita a certas partes do corpo humano: as genitálias, que acabam funcionando como resumidoras da identidade compulsória entre sexo/ gênero/ práticas e orientação de desejo e propõe a Contrassexualidade (conferir o Manifesto contrassexual), como estratégia efetiva de denúncia e desmonte da tutela sobre corpos, gêneros, desejos; ao revelar quantas próteses refabricam nossos corpos (das mais "simples, básicas ou reversíveis", como óculos, adereços como piercings e brincos e maquiagens a próteses de silicone, próteses para membros perdidos em sobreviventes de guerras e acidentes, tatuagens etc). Logo, nossos corpos não são tão monoliticamente engendrados segundo uma estereotipia imposta. Pessoas de ambos os gêneros, mesmo identificadas com a heteronormatividade, estão sujeitas às tantas e diversas próteses mencionadas. Mulheres mastectomizadas em decorrência do câncer ou de cirurgias estéticas deixam, então, de ser mulheres? E aqui entro numa fenda que me abrigará no pensamento pela via trans... Prefixo que precede a ideia contida em trans-formação; naquilo que transcende...

Eu, uma mulher supostamente cisgênera, mas de aparência andrógina (algo que o texto não pode revelar), começo a esboçar uma fala que revela a construção dos corpos de todo e cada indivíduo, identifique-se ele ou ela com qual gênero for (o 
da genitália que exibe ou não), ou ainda, identifique-se como 'não-binário': ou seja, aquele que não se quer ver aprisionado a uma performance unívoca seja 'masculina' ou 'feminina'. É o caso, por exemplo, de mulheres trans que não desejam a cirurgia de redesignação da genitália e não aparam pelos do corpo, mas se identificam como mulheres e exibem uma performance de indumentária, de linguagem ou de comportamento que identificam como feminina.

E estou a escrever sobre um tema que se assenta em um terreno minado, em um momento em que as demandas e disputas por representatividade se confundem com as ideias de representação... Mas seguirei refletindo. Não ignoramos aqui a discussão e a reivindicação envolvidas na ideia de 'lugar de fala'; mas acrescemos que há, também, 'lugar de escuta' e, para que haja, ainda, 'lugar de partilha', acreditamos que devemos escutar ao máximo diversas fontes (o que, em si, já é de uma complexidade ímpar), sobretudo para "descolonizar" o modo de olhar: operação que exige uma atenção permanente para as armadilhas do percurso e uma busca constante. E se aqui falamos, em outro dos elementos-tema que são as representações das performances de gênero (sobretudo em interface com as linguagens artísticas), os desdobramentos só se multiplicam.

Representar já é uma operação ficcional e quase inescapável. Se tivermos a coragem de admitir que, até quando fazemos supostas confissões íntimas, elaboramos nosso olhar, tentamos autocomiseração, pintamos e colorimos a cena relatada (até quando deliberadamente parecemos cruéis com nós mesmos). Por isso que acerta no alvo a ficcionista nigeriana Chimamanda Adichie, em sua palestra $O$ perigo de uma história única (proferida ao canal TED - Technology, Entertainment, Design - em 2009), quandoadverteque épreciso multiplicar as histórias e multiplicar quem as conta. Mais ainda se a representação é literária, o compromisso é com muito além da suposta 'verdade', mas com a invenção, que acaba por desnudar ainda mais... Somos mulheres todas, como venho frisando desde o início, e as intersecções de todos os aspectos e traços individualizantes de certos grupos e realidades devem ser sublinhados em suas demandas especiais, mas nunca sobrepostos em importância à compreensão da empatia que une a todas, pois somos todas historicamente esmagadas por machismo e patriarcalismo. São tantas as exclusões e as formas de violência segundo as quais vamos sendo 'deslegitimadas' como mulheres, como sujeitas ativas e autônomas...

Como não pensar em um dos processos de criação em que estou imersa já desde 2016, noqual seveem interligadas minhas vivências como professora de literatura, poeta e criadora em dança e teatro e as questões atravessadas neste texto? Esse relato deve, então, dar mais uns saltos para trás; como a dialética do próprio processo histórico, aqui não pensado na perspectiva da suposta 'grande ciência humana' engendradora de um discurso unívoco e tradutor de vozes coloniais dominantes, e veremos a implosão de discursos/ práticas engessados/as e a polinização de novas sementes de relatos. Vou soltando alguns fios, depois os ligarei em um tecido...

Abre-se a cortina e entra em cena, então, o exemplo que quero trazer à tona a esta altura: o Coletivo de Teatro Bárbara Idade, nascido em 2007 , formado por egressas do Curso de teatro para terceira idade oferecido em uma das unidades do Sesc/PE, em 
Recife. O grupo iniciou com algumas atrizes e foi crescendo, sempre dirigido pelo professor, ator e encenador Rodrigo Cunha Santos. Na trajetória de produções, a poesia foi o caminho primordial de expressão do grupo. Inicialmente composto apenas por atrizes, atualmente são nove, e há alguns anos juntaram-se dois atores ao Coletivo. Os trabalhos se iniciaram em 2007 e seguem até hoje, com vários espetáculos ao longo deste tempo.

Como estratégia adota-se que cada artista criadora escolhe os poemas que a tocam e isso reforçou a relação direta existente entre a visão de mundo da artista e a sua criação, levando-se em consideração a ideia de Pareyson: "que o artista arrasta para a sua arte os seus ideais filosóficos, morais, políticos, religiosos, e, de tal forma deles impregna as suas obras, que estes assumem a função daqueles diversos valores". (1997: 38) Aspectos das relações simbólicas pessoais e de construção das identidades da aluna/artista/senescente vão se revelando a partir das escolhas tomadas.

É importante destacar que, como pesquisa de linguagem cênica, se manteve uma tendência de os espetáculos entrecruzarem literatura, teatro, artes visuais e cinema. Na encenação de 2013, por exemplo, baseada na obra de Manuel Bandeira, se fazia o uso projeções de depoimentos das atrizes e do ator sobre suas relações com o processo de criação, além de trechos do filme "A filha do advogado" (dirigido por Jota Soares e produzido no Recife em 1927) com imagens desta cidade na década de 1920, de uma videoarte produzida com imagens de três das atrizes envoltas em tecidos e realizando movimentos sutis e sensuais e, ainda, a projeção de fotografias das integrantes do grupo em fases diversas de suas vidas. Desse modo, o coletivo se aproximava de sua própria cosmovisão e das tomadas de consciência sobre si mesmas como sujeitas e como grupo. Enfatiza-se que não era ainda uma demanda explícita, mas o feminino se insinuava como uma questão latente desde sempre.

Em Pedagogia Profana: danças, piruetas e mascaradas, Jorge Larrosa nos revela que "um dos efeitos da tomada de consciência é que cada um sente a necessidade de reescrever, a partir desse momento de mudança, sua própria história” (2010: 32). E assim se deu com o Coletivo de Teatro Bárbara Idade. Qual seria o mergulho seguinte, após se puxarem os primeiros véus que descortinavam as identidades processuais e as subjetividades dessas sujeitas-atrizes? Os mergulhos mais fundos se iniciavam... Ainda seguindo com as palavras de Larrosa:

O homem se faz ao se desfazer: não há mais do que o risco, o desconhecido que volta a começar. O homem se diz ao se desdizer: no gesto de apagar o que acaba de ser dito, para que a página continue em branco. Frente à autoconsciência como repouso, como verdade, como instalação definitiva na certeza de si, prende a atenção ao que inquieta, recorda que a verdade costuma ser uma arma dos poderosos e pensa que a certeza impede a transformação. (2010: 41) 
Atente-se, as palavras de Larrosa são pertinentes e fecundas, mas aparece não casualmente o termo generalizador (e sem problematização alguma) "o homem", como o representativo 'por excelência' do ser humano. Trazemos essa citação, agora não por acaso, exatamente quando vamos mencionar a virada de rumos que se dá no coletivo. É ao se começarem as conversas para definição da pesquisa a se iniciar para o trabalho seguinte que a maioria feminina (agora com dois atores e o diretor) se questiona sobre a condição da mulher e resolve focar o olhar em poetas mulheres, através das quais poderiam, no novo processo de pesquisa, ecoar suas relações com o gênero e o mundo circundante. Queriam darvozes e sentidos a suas vivências marcadas pelo signo feminino e incluir nisso as relações daqueles homens com o feminino, pois não se trata de apartar o grupo.

E a busca percorreu escritos de Cecília Meireles, Cora Coralina, Elisa Lucinda, Marina Colasanti... As atrizes propuseram elencar poemas de diversas autoras e mais uma vez o diretor Rodrigo recorreu à proposta de elas sinalizarem os poemas que lhes pareciam capazes de as traduzir, entretanto não encontravam um diálogo entre as escolhas, um fio que conduzisse à criação. Neste ponto do processo é que sou convidada a me juntar ao Coletivo, que já tinha visto como espectadora nos trabalhos anteriores, para elaborar (junto ao grupo) a dramaturgia do espetáculo.

Nos encontros semanais, comecei apenas observando o processo de trabalho, os jogos teatrais, conhecendo a seleção de poetas que tinham elencado até então e buscando escavar as razões (conscientes, simbólicas, afetivas e, até, especular as obscuras vias) para tais escolhas. De pensar o repertório das atrizes e dos atores a provocar que conhecessem novas fontes e se perguntassem as motivações para as escolhas, comecei a inquietar e perturbar mais e mais as certezas do grupo.

Uma das primeiras fissuras: propus - e foi aceito por todas - que experimentássemos uma primeira efetiva ação de mudança político-linguística entre nós: se somos uma maioria massiva de mulheres (eu e mais a assistente de direção somadas ao todo, ficamos em onze), entre nós havendo apenas três homens, por que não instituíamos que nossos plurais seriam sempre no feminino? Já nos rebelávamos contra uma dimensão da língua que obriga a flexão masculina no plural se houver um homem que seja...

Aqui propomos e começamos a por em prática uma estratégia política efetiva ao nível da linguagem, algo que ecoa uma prática dos movimentos de militância de grupos não-hegemônicos no terreno do gênero; como o artifício de se usar o 'X' em lugar de marcar o gênero binário com 'O' ou 'A'; ou o uso de uma espécie de 'gênero neutro' (que existia no latim e não existe na gramática normativa da língua portuguesa), flexionando-se o final das palavras em 'E': 'coleguEs', 'todEs'... No caso do Bárbara Idade, nosso desejo é de marcar o feminino como plural majoritário, uma marca de militância feminista no plano linguístico que esperamos e cremos ver reverberar em mudanças pragmáticas de olhar e ação na vivência do grupo. Afinal, língua é poder; nomear confere poder; performance de linguagem também traduz identidade, reflexão, protagonismos... 
Dando seguimento à desconstrução dos hábitos e dos procedimentos, fui levando novos textos, buscando não só a poesia em sua forma mais convencional, mas alargando a ideia de poética, a de história, a de gênero, a de identidade... E, acrescendo à receita o ingrediente da pluralização, levei ao grupo o texto da palestra da escritora nigeriana Chimamanda Adichie aqui já mencionado. Queria assim unir a marca de voz de uma mulher negra, nativa de um país do continente africano (colonizado pela exploração e pelo imperialismo europeu como nós) que é uma ficcionista crítica e militante do feminismo e a noção de que experiências individuais são múltiplas, diversas, plurais e, mesmo assim e por isso mesmo, capazes de acessar e impactar a sensibilidade humana. Eis queecoa e cola em todas nós o trecho da fala de Chimamanda em que ela frisa:

Histórias importam. Muitas histórias importam. Histórias têm sido usadas para expropriar e tornar maligno. Mas histórias podem também ser usadas para capacitar e humanizar. Histórias podem destruir a dignidade de um povo, mas histórias também podem reparar essa dignidade perdida. (2009: 17’37")

O teatro, este lugar em que forjei tanto da minha subjetividade e identidade, como artista, como sujeita, como militante e até como professora, é terreno por excelência do político em seu sentido mais intrínseco e mais fecundo, na esteira do que nos diz Dénis Guénoun, em A Exibição das palavras: uma ideia (política) do teatro (2003), pois nos põe impreterivelmente em presença, reunidos em uma assembleia. A cada ensaio eu via a colheita de mais e mais histórias pessoais daquelas pessoas/ mulheres/atrizes sendo partilhadas. Eram vidas de enfrentamentos, resistências na busca de afirmar desejo, trabalhar, viver, criar filhos e sustentar arranjos familiares; existir como idosas em uma sociedade que descarta mais e mais rápido a tudo e a todas; sobreviver a violências seguidas e estruturais.

Não era mais possível adiar: essas vozes tinham que explodir na cena, suas questões eram urgentes e jaziam há muito esperando ganhar corpo e cena. A noção de o quanto o feminismo também estava por esquecer as mulheres senescentes, entre suas pautas de tantas urgências, acordava mais e mais em mim o quanto as novas auroras ao feminismo não podem descartar demandas que podem parecer antigas ou superadas, mas efetivamente seguem se acumulando. Mulheres trans, mulheres negras, mulheres pobres, mulheres periféricas geograficamente, mulheres em situações de extrema vulnerabilidade: mulheres todas, em graus diversos de opressão e protagonismos possíveis, ainda e sempre em necessidade de luta, sem hierarquizações, mas sim com extrema coesão e consciência de que há muitas paredes a quebrar.

No contexto do Bárbara Idade, então, mudamos os ventos que nos sopram as velas; seguimos lendo dissonantes vozes femininas; levo ao grupo Hilda Hilst (criadora de Hillé, a obscena senhora D. que resolve habitar o vão embaixo da escada, isolandose, mas mesmo assim não contendo a lucidez de sua voz de sexagenária fêmea que questiona, inquire Deus e os homens, na figura de seu falecido companheiro Ehud, 
reivindicando direito ao verbo, ao gozo, a gerir rédeas de seu destino). Conversamos sobre Clarice Lispector, outra desviante voz que afirma a fêmea existência com força descomunal. Novamente incorporo a voz inquieta e lúcida de Chimamanda Adichie, agora em seu livro Sejamos todos feministas:

Então, de uma forma literal, os homens governam o mundo. Isso fazia sentido há mil anos. Os seres humanos viviam num mundo onde a força física era o atributo mais importante para a sobrevivência; quanto mais forte a pessoa, mais chances ela tinha de liderar. E os homens, de maneira geral, são fisicamente mais fortes. Hoje, vivemos num mundo completamente diferente. A pessoa mais qualificada para liderar não é a pessoa fisicamente mais forte. É a mais inteligente, a mais culta, a mais criativa, a mais inovadora. E não existem hormônios para esses atributos. Tanto um homem como uma mulher podem ser inteligentes, inovadores, criativos. Nós evoluímos. Mas nossas ideias de gênero ainda deixam a desejar. (2015: 21)

Também nossas ideias de autoridade se veem postas em perspectiva, quando acrescentei ao caldo de leituras os gritos da "beira do mundo"... Pois, se é pra romper interditos, expressar silêncios, por em cena mulheres atrizes e vidas não hegemônicas, que destoam das elites: elas são negras, brancas e mestiças; têm origens diversas; são mulheres que não quiseram casar ou parir; enquanto há outras que casaram e permanecem casadas; outras se relacionaram em vários casamentos ou apenas ajuntamentos; ou até se relacionaram com homens bem mais jovens; são desejos de vidas profissionais; são relatos multifacetados de violências e solidariedades... então, que se juntem ao coro Estamira (a catadora de lixo que viveu no lixão do Gramacho, no Rio de Janeiro, e se dizia ela mesma 'a beira do mundo', em sua consciência de falar da margem e saber muito bem quem são seus opositores - "os espertos ao contrário"); Stela do Patrocínio (negra, ex-empregada doméstica que foi internada e viveu em um manicômio no Rio de Janeiro - a Colônia Juliano Moreira - por cerca de duas décadas, onde seus versos acabam sendo gravados por ex-alunas de Nise da Silveira que lá implementaram a abordagem de arte terapia proposta e executada por esta brilhante mulher) e, ainda, Carolina Maria de Jesus (negra, favelada, catadora de lixo e escritora que em 1960 converte-se em best seller ao ver publicados seus escritos: do diário intitulado Quarto de despejo a outros títulos posteriores).

E definitivamente os relatos de vida das atrizes ganham o foco, deixando as vozes poéticas como costuras em segundo plano, como sons subjacentes. Nascem as (H)estórias mínimas, e esse nomear reflete a quebra da prevalência da historiografia oficial e sua produção de estereótipos e apagamentos de sujeitos comuns, mulheres, marginais de toda sorte; este $\mathrm{H}$ maiúsculo aprisionado em parênteses é o confisco que operamos de uma história única e machista, escrita por Homens. Sai de cena a prevalência máscula; nossos relatos são as ficções de construções de si dessas mulheres 
que podem tecer suas próprias vidas (“Agora, ninguém mais bota palavras na minha boca", diz uma delas em cena).

A essas discussões de identidade gendrada adicionamos a fala de Kathryn Woodward (2007) quando nos lembra que muitas vezes a representação da identidade de um povo está diretamente ligada à figura masculina, e que às mulheres cabem posições-de-sujeito delimitadas pelos homens a partir de si próprios como ponto de referência. (H)estórias Mínimas busca inverter o olhar acerca da construção da identidade a partir do masculino, levantando na criação da cena discursos de representação da mulher majoritariamente construídos pelas mulheres-atrizessenescentes, tornando-as matrizes e geradoras das construções poéticas do espetáculo. Ainda segundo Woodward, as práticas de significação e os sistemas simbólicos posicionam o sujeito, dando sentidos à sua experiência, permitindo ainda que o sujeito perceba a si e o que pode vir a se tornar; desse modo levar as diversas histórias das atrizes à cena torna-se um ato político e artístico por evidenciar as vozes de mulheres que foram por vezes silenciadas em suas trajetórias de vida. O prefixo trans aqui alcança nossa proposição desde o início: a ideia de transcender as amarras de várias naturezas que vão esmagando as mulheres.

Estamos, para agravar o cenário onde nascem os relatos, no nordeste do Brasil, região em que o patriarcado tem raízes fundas. Invocamos o universo de Guimarães Rosa e suas Primeiras estórias, assim grafadas com "e" para dar conta dos tantos 'outsiders' que protagonizam os relatos deste mestre mineiro da palavra: crianças, mulheres, santos, marginais, jagunços; toda a poesia da terceira margem se irmana a nós neste desejo de romper a lógica pátria e instaurar novas Mátrias, novas sororidades, novas simpatias: do grego, o 'sentir com', a possibilidade de essas mulheres senescentes terem voz, corpo visível e desejo; pulverizarem suas formas muito particulares de feminismos, adentrarem produtivamente e sem concessões a cadeia produtiva da arte fazendo de suas vivências a matéria dramática e as poéticas da cena.

E trata-se de trazer o pessoal à tona, sim, posto que "o pessoal é político", e este é um lema do feminismo, como reitera Carol Hanisch (200o) em seu trabalho assim nomeado. Afinal, as maiores revoluções das mulheres se tecem no cotidiano, aparentemente miúdo, de criar filhos, de desempenhar jornadas triplas, de "minar de dentro" o sistema que as quer submissas. Que feminismo queremos e fazemos? O de essas mulheres poderem dizer-se em cena: falar do desejo, da sexualidade, da condição de profissionais em várias áreas que hoje são atrizes (sem concessões a apenas um "teatro de passatempo para senhoras aposentadas", porque são sujeitas ativas). Eis que somos, então, todAs, a teia Bárbara Idade! E as teias identitárias se pulverizam...

Vários temas considerados tabu vieram à tona e os posicionamentos de cada integrante ao longo do processo renderam discussões sobre as escolhas de vida de cada uma e suas reverberações nos dias de hoje. Inevitavelmente o grupo passou a agir como uma rede de fortalecimento de mulheres gerando entre si o respeito mútuo e reconhecimento da diversidade entre elas. Percebemos a força que elas têm na coletividade corroborando, reitera-se mais uma vez, o discurso de Carol Hanisch: "One of the first things we discover on these groups is that personal problems are political 
problems. There are no personal solutions at this times. There is only a collective action for a collective solutions." (HANISCH, 2000, p.114)

Evidenciou-se ao longo do processo de criação da nossa dramaturgia o quanto as histórias mínimas, breves, sutis, aparentemente banais dessas mulheres se entrecruzavam, se espelhavam e revelavam para as mesmas que elas não estavam isoladas nas suas lidas diárias. É necessário explicitar que, inicialmente, o grupo apresentou uma certa resistência a abandonar os poemas e abrir suas histórias na coletividade (resistência de quem se habituou a ser calada); no entanto, logo que foi vencida esta barreira, uma enxurrada de relatos tomou os laboratórios de criação cênica. Assim, repetimos, vieram os relatos: de procura por empregos, a sujeição ou não ao marido, assédios em local de trabalho, a alegria e as agruras da maternidade, relação com homens mais jovens, casamento, perdas de parentes queridos, dificuldades e libertações, sexualidade e corpo desejantes de mulheres idosas, as transformações todas a que aludimos no princípio. Rompem-se silêncios de sujeitas tradicionalmente apagadas e sem voz!

As criações cênicas realizadas pelas atrizes retroalimentam o próprio grupo quando são compartilhadas as vivências a partir da reconstrução poética das (h) estórias de cada atriz. Cada escolha do que pulsa como urgente em uma criadora reverbera nas demais colegas de cena no momento em que as histórias são trocadas e reenunciadas/ reincorporadas como se fossem próprias de quem conta. A esta altura é importante informar que, no jogo da encenação, passamos pela etapa de desapego de cada uma de suas histórias como 'partilhas ou patrimônios' pessoais, pois queríamos o que em cada relato nos fazia sensíveis umas às outras (lembramos que aqui se diz o plural, incluindo os homens no processo, no feminino).

Então, jogo entre real e ilusório se estabelece nas construções em que cada artista conta uma (h)estória sua ou não, se afeta pelos relatos, funde-se com (h) estórias suas, ou ainda quando duas pessoas contam a mesma (h)estória. Questões como violência de gênero, por exemplo, ganham outros sentidos quando encenadas pelos homens, causando um estranhamento e deslocando o olhar acerca do trato da sociedade. O 'afetar-se' torna-se diretriz e prática na elaboração das cenas, sendo cada criação discutida acerca dos sentidos múltiplos que cada detalhe das histórias contém.

O Bárbara Idade neste processo tem redescoberto um possível caminho para o fazer teatral e para a representação deste universo de mulheres senescentes, reconstituindo sua identidade enquanto grupo e se afetando enquanto indivíduAs a partir da experiência de alteridade na relação poética com a história da outra. O olhar lançado sobre si mesmas enquanto mulheres a partir da descoberta das potencialidades poéticas de cada história de vida levou a uma representação simbólica de si carregada de decisões políticas de poder feminino. A pesquisa de linguagem teatral realizada pelo grupo expressa uma inquietação com o tempo presente e traz uma peculiar forma de lidar com o tempo, posto que passeamos por histórias de diversos momentos de vidas pessoais e momentos políticos no país reverberando sobre a vida privada de cada artista. E, assim, ecoa em cada pessoa/sujeita na plateia! Dessa forma o Bárbara Idade ressignifica o olhar e os conceitos pré-existentes acerca do que é ser mulher e, 
sobretudo, idosa. Por meio dessa experiência, quero alargar a percepção e revelar a complexidade das pautas de um feminismo efetivamente abrangente e inclusivo; por meio do qual possamos nos dar mãos e abraçar as pautas comuns e específicas sem fissurar as lutas e a mobilização. Por mais utópico e difícil que pareça, insisto: sejamos todas feministas e aliadas.

Para seguir desdobrando as possibilidades de representação ${ }^{1}$ (no sentido de criação artística produzida por um olhar sobre personagens complexamente criadas), poderia aqui invocar ainda as tantas personagens transgêneras, adentrando outros universos de representação literária, como as que povoam o universo ficcional e teatral, além dos desenhos cômicos, do argentino Raul Botana (o Copi), como em $O$ Homossexual ou a dificuldade de se expressar (1971); O Baile das Loucas (1983); A Guerra dos pederastas (1982), obras protagonizadas por uma extensa galeria de personagens trans que levam ao extremo e à cena a quebra das imposições heteronormativas, das prisões identitárias na estereotipia que insiste em igualar genitália/ sexo e identidade de gênero/ orientação de desejo ... Ou ainda os contos escritos por Chico Ludermir em A História incompleta de Brenda e de outras mulheres (2016), elaborados a partir de relatos ao autor de mulheres trans ou travestis brasileiras de diversas idades, no nordeste do Brasil. São pulverizações, multiplicações, não obrigatoriamente levadas a cabo apenas pelas próprias vozes de mulheres trans, mas a elas simpáticas e por elas afetadas, para "quebrar as paredes" e, como escreve Maria Clara Araújo (mulher e ativista trans), no prefácio ao livro de Chico, nos permitir percebermos "a importância simbólica da contação dessas narrativas, do reconhecimento delas (...). Só assim que conseguiremos visibilizar e/ou colocar em discussão as vivências abjetas" (2016: 12).

Aqui, trouxe apenas algumas reflexões diversas e provocações na tentativa de contribuir a um alargamento do pensamento e da práxis feminista, no sentido de fortalecer a interseccionalidade e uma via trans, ou seja, que consiga transitar entre as demandas que nos unem como seres: mulheres, negras, desejantes, sexuais, cambiantes, trans, heterossexuais, lésbicas, homens não-machistas e não-misóginos como é urgente ser!

\section{Referências}

ADICHIE, Chimamanda. (2009). O perigo de uma história única (proferida ao canal TED - Technology, Entertainment, Design: https://www.geledes.org.br/chimamandaadichie-o-perigo-de-uma-unica-historia/).

(2015). Sejamos todos feministas. São Paulo: Companhia das Letras.

1 É importante frisar que estamos aqui falando de representação como noção de criação artística e não discutindo a ideia ou estratégias de representatividade de grupos específicos (sejam mulheres senescentes, mulheres trans, dissidentes sexuais etc). 
ARAÚJO, Maria Clara. “Prefácio”. In: LUDERMIR, Chico. (2016). A História incompleta de Brenda e de outras mulheres. Rio de Janeiro: Confraria do Vento.

BUTLER, Judith. (2013). Problemas de gênero: feminismo e subversão da identidade, Rio de Janeiro: Civilização Brasileira.

COPI. (1971). L'Homosexuel ou la difficulté de s'exprimer. Paris : Christian Bourgois. (1982). La Guerre des pédés. Paris : Albin Michel. (1983). El Baile de las locas. Barcelona: Anagrama.

FOUCAULT, Michel. (1988). História da sexualidade: a vontade de saber. (volume 1). Rio de Janeiro: Graal.

GUÉNOUN, Dénis. (2003). A Exibição das palavras: uma ideia (política) do teatro. Rio de Janeiro: Teatro do Pequeno Gesto.

HANISCH, Carol. (200o). “The persona lis political”. In: CROW, Barbara A. Radical feminism: a documentar reader. New York: New York University Press.

LARROSA, Jorge. (2010). Pedagogia profana: danças, piruetas e mascaradas. Belo Horizonte: Autêntica.

PAREYSON, Luigi. (1997). Os problemas da estética. São Paulo: Martins Fontes.

PRECIADO, Paul B. (2014). Manifesto contrassexual, São Paulo: editora n-1.

STOKLOS, Denise. (1993). Teatro essencial. São Paulo: Denise Stoklos Produções.

WOODWARD, Kathryn. (2007). "Uma introdução teórica e conceitual”. In: SILVA, Tomaz Tadeu de. (org). Identidade e diferença. Petrópolis/ Rio de Janeiro: Vozes.

WOOLF, Virginia. (1990). Um teto todo seu. São Paulo: Círculo do Livro. 